\title{
Sexual Counseling in Gynecological Cancers: A Case Report
}

\author{
Çiğdem BíLGE, ${ }^{1}$ Ergül ASLAN'
}

'Department of Nursing, Istanbul University of Florence Nightingale School of Nursing, Women Health and Diseases Nursing, Istanbul-Turkey

\section{Introduction}

Gynecological cancers negatively affect the identity and sexual lives of women.[1] Treatments applied in this process affect the sexual lives of women negatively. [2] Although sexuality is an undeniable aspect of individuals, it is observed that healthcare professionals face difficulties in dealing with sexual health. The reasons for this are problems related to privacy, prejudice, lack of knowledge, wrong expectations and attitudes, and beliefs and terminology developed by the applicant depending on his/her culture.[3] Models used in the questioning of sexual life during the care process increase the quality and effectiveness of sexual counseling services. [4,5]
PLISSIT model, one of the useful guidelines of sexual counseling, consists of four stages as follows.

Permission: At this stage, the patient is assured that they can express their feelings. Limited Information: In the limited information stage of the PLISSIT model, information about the effect of cancer on sexuality, sexual functioning of treatment, and sexual health is given. Specific Suggestions: This stage includes specific suggestions and information recommended to the patient to make their sexual lives more satisfying. Intensive Therapy: Intensive therapy stage is used in cases wherein the three steps of the model are not successful. The patient is referred to a sexual therapist who specializes in intensive therapy. [5]

The purpose of this study was to describe the sexual 
problems experienced by a woman receiving gynecological cancer treatment and the effectiveness of the sexual counseling conducted in accordance with the PLISSIT model.

\section{Case Report}

A 31-year-old, nulliparous, married patient presented to the Istanbul University Faculty of Medicine Gynecologic Oncology Outpatient Clinic with irregular menstruation. The patient had a university degree and she had been working as a clerk. After pelvic examination was performed, the patient who underwent conization process was diagnosed with stage $1 \mathrm{~B} 1$ cervical cancer, according to FIGO staging. Then, the patient underwent radical trachelectomy on March 21, 2016, and received three fractions of brachytherapy in a week at the Institute of Oncology in Istanbul University. Vaginal fistula developed in the patient after the surgery. She received no intervention for the vaginal fistula.

"Women's Sexual Health Training Manual" was prepared in accordance with the literature before the interviews. Opinions of four specialists were obtained for the training manual. A pilot study was conducted with 10 patients, and the booklet was reevaluated for compliance. The prepared training manual was given to the patient during the counseling and this manual was used in the second and third interviews. Each session lasted an average of $45 \mathrm{~min}$.

The first encounter and interview with the patient was conducted after surgery and medical treatment. The patient was visited in the first control after the treatment to question about her sexual life. In the interview, the Female Sexual Function Index (FSFI) and the Sexual Satisfaction Scale for Women (SSSW) were used to objectively measure the level of sexual satisfaction. Sexual history was also taken along the forms filled as face-to-face. Decreased vaginal lubrication, dyspareunia, avoidance of sexual intercourse, and difficulty in orgasm in her history were determined to be the most common sexual problems experienced by her. In addition, the patient was also observed to have exhaustion, fatigue, and urinary incontinence. In the first interview with the patient, the "permission" stage of the model was completed by discussing the psychological and physiological changes after the treatment, and an appointment was made 1 week later for the second interview.

In the second interview, information about gynecological cancers and psychosocial situations in terms of sexuality was given by making a short informing with the training booklet with pictures illustrating the structure and function of the reproductive organs. It was as- serted that surgery, radiotherapy, or chemotherapy in the treatment of gynecological cancers cause impairment in the quality of life of the patient and her family. While vaginal bleeding, fatigue, abdominal pain, and postcoital bleeding from the gynecological cancer symptoms disrupt the woman's sexual health before the treatment; physical symptoms such as vaginal shortening, deterioration of elasticity, decreased lubrication, vaginal stenosis, pelvic nerve damage, fistulas, fatigue, diarrhea, insomnia, infertility, and postcoital bleeding are stated to negatively affect sexual health after the treatment. The "limited information" phase of the model was thus completed. An appointment was made a week later for the third interview.

The third interview was aimed to regulate sexual function. The cycle of sexual response was explained. During this interview, it was explained that the decrease in sexual desire and sexual activity may cause problems between partners. As the patient's anxiety increased, pleasure and desire decreased, and training on not focusing only on sexual intercourse was given to eliminate the ideas feeding the anxiety. By encouraging the patient to imagine a sexual fantasy, her erotic thoughts and fantasies were supported. Thus, it was ensured that the perceptions became positive. The patient was encouraged to practice everyday an exercise that aimed to examine and identify the perineal region with the help of a mirror. Homework was given to them to strengthen their relationship, such as bathing with their husband at home, going to bed at the same time, and preparing dinner together. The patient was also asked to imagine a sexual fantasy and write that down on a piece of paper. It was stated that providing vaginal lubrication before sexual intercourse will decrease pain during intercourse, and this could be achieved by increasing the time for foreplay. The patient stated that she had some prejudices against masturbating. It was explained to the patient that masturbation is an exercise that increases sexual pleasure, improves vaginal lubrication, and should be done with soft circular movements without being too hard, and it would be beneficial to do by herself in the first stage. In addition, it was also explained that sexual position wherein the woman is on top will decrease the penetration, thus easing dyspareunia. In addition, the patient was also told that she can use water-based vaginal lubricants to reduce pain during penetration. At this stage, the patient began to keep a sexual desire journal. Performing Kegel exercises during sexual intercourse will ensure that her focus is only on her perineal muscles by closing her thoughts to the outside world; this will increase the sexual pleasure and stimulation. At the end of the interview, a training manual with pictures supporting 


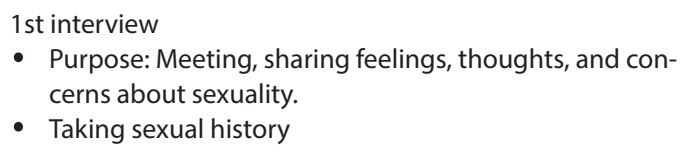

- Purpose: Meeting, sharing feelings, thoughts, and concerns about sexuality.

- Taking sexual history

3rd interview

- Purpose: Regulating sexual function

- Providing specific suggestions and training to guide in the correction of sexual problems

- Purpose: Giving limited information

- Giving information about gynecological cancers

- The effects of applied treatments on sexuality and giving information about these effects

- Helping individuals to acquire the skill to cope with sexual problems

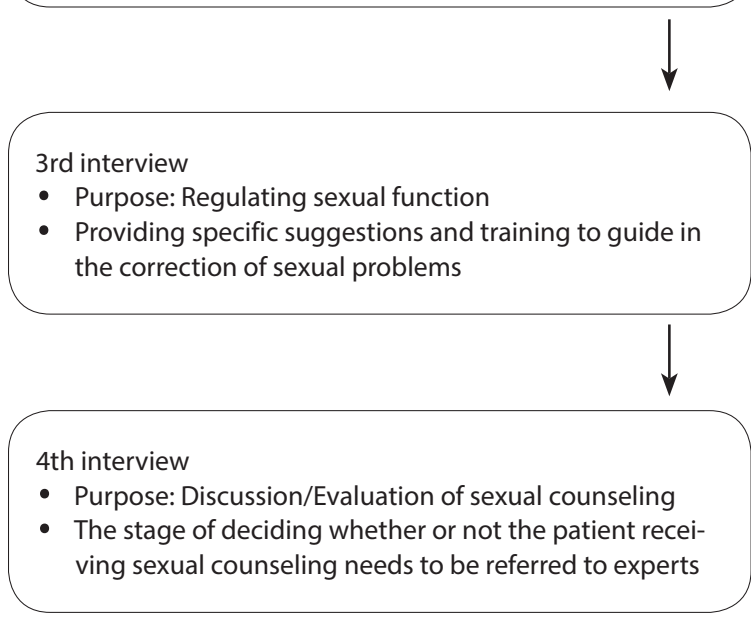

Fig. 1. Summary of sexual counseling interviews.

what was told was given to the patient. An appointment was made 2 weeks later to complete the suggestions and homeworks, and "Specific Suggestions" part of the model was applied.

One week after the third interview, the patient was contacted via phone to evaluate the extent of the sexual relationship and to observe the applicability of the specific suggestions. The patient stated that she was satisfied with the process, she applied a big part of the homework and suggestions, and she and her husband were highly satisfied.

The fourth interview aimed to evaluate the extent of the sexual relationship and sexual counseling provided. At this stage, the patient stated that she fantasied before having sexual intercourse and that she even taught her husband. She and her husband bathed together, which was very useful for preparing for sexual intercourse. She also stated that she did not fill her sexual desire journal in the first period since she had no sexual desire; however, she started to fill the journal after her homework and she expressed that seeing that her sexual desire increased in written form increased her motivation. She stated that in the initial days, she performed the mirror exercises by only examining the perineal region, but then later proceeded to touching the perineal region. She stated that her attitude toward masturbation has changed, and she masturbated twice in this period. She observed that her vaginal lubrication increased after masturbation. She preferred the position where she was on top during penetration and stated that the pain was less in this position. In addition, she stated that she used the figures given in the training manual for different sexual positions and it was very helpful. She and her husband planned activities they can do together during this period. She also stated that her sexual desire and pleasure strengthened her relation with her husband. The patient stated that the sexual counseling interviews since the first steps till the current step were very useful, increased her sexual desire, and eased the pain she felt during sexual intercourse. She also stated that she usually had orgasms but not at every intercourse, and her sexual satisfaction increased and she felt better spiritually. Thus, the "discussion phase" of the model was realized. During the final interview, the patient was asked again to fill FSFI and SSSW and the scores of the scales were determined to increase significantly.

\section{Discussion}

Gynecological cancer and its treatment adversely affects the quality of life of women from physical, mental, and social aspects.[6,7] It is observed that women with gynecological cancers do not see the problems they experience in their sexual life as priority from the treatment, or they do not get adequate support to solve these problems and they are alone in the solution phase. Therefore, it is necessary to provide sexual counseling services to prevent or solve sexual problems that may be experienced during the diagnosis and treatment of gynecological cancers. $[1,8,9]$

Many studies in the literature have revealed that women with gynecological cancers report lower sexual desire and satisfaction than healthy women. As a result of the study conducted by Tang, Lai, and Chung to compare the sexual satisfactions of healthy women $(n=105)$ and women who received gynecological cancer treatment $(n=134)$, it was determined that while sexual dissatisfaction was not observed in healthy women, sexual dissatisfaction was high in women receiving gynecological cancer treatment (68.3\%).[10] In this case, the patient expressed that she received 
brachytherapy along with the surgical treatment and experienced sexual anorexia, dyspareunia, inadequate vaginal lubrication, difficult orgasm, and sexual dissatisfaction.

In the study conducted by Chun in 2011 on 61 women with cervical, ovary, and endometrial cancers, the sexual functions of the women were followed. In the study designed as an experimental-control study, the women were divided into two groups including experimental and control groups. A 6-h integrated (2 h per session) program reflecting the physical and psychosocial aspects of female sexuality developed based on PLISSIT model was applied to the experimental group. Both groups were evaluated with FSFI. At the end of the study, it was reported that the 3-week PLISSIT model sexual program was effective in increasing the sexual functions of women with gynecological cancer and the nurses can provide contribution for the women to fulfill their sexual functions using the program.[11] In 2013, Nho prepared a sexual health promotion program to improve the sexual lives of women with gynecological cancer and their spouses. The comprehensive program (including 90 min per session, four sessions) was prepared based on the PLISSIT model. The study including 43 couples was planned as an experimental-control study. As a result of the study, the sexual health promotion program was reported to be effective in improving sexual function and reducing sexual problems.[12] In a study conducted in Iran for the purpose of evaluating sexual satisfaction in women of reproductive age, sexual satisfaction was provided to the women through telephone and face-to-face interviews. In a randomized controlled study, 46 women were counseled, and it was observed as a result of the study that the sexual satisfaction levels of the women after the counseling significantly increased.[13] In this case, face-to-face sexual counseling interviews based on PLISSIT model were planned to decrease the time it took to reach orgasm, to increase sexual desire and the frequency of sexual intercourse, to increase vaginal lubrication and thus decrease dyspareunia. The program based on a total of four sessions including 45 min per interview lasted for 5 weeks. In addition to the expressions of the patient, she was asked to fill FSFI and SSSW in the first and final interviews to evaluate the sexual relationship dimension of the patients. As a result of sexual counseling, it was observed that the sexual function of the patient improved and her sexual satisfaction level increased.

Consequently, sexuality is a multidimensional concept and is negatively affected by diagnosis and treatment of gynecological cancer. Along with gynecological cancer treatment, women are in an effort to regain their identity, values, priorities, and sexual partner responsibility. In such a process, support systems and counseling services play an important role in eliminating their anxieties and concerns. When a sexual counselor assesses the client, the counselor should approach the individual with a holistic perspective and ignore some moral and legal situations. It is necessary to determine the limits of treatment well. Matters such as honesty, privacy, and confidentiality should be prioritized. Information shared by clients should be listened with sensitivity. Clients should be interviewed in a professional manner.

Peer-review: Externally peer-reviewed.

Conflict of Interest: The authors declared no conflicts of interest with respect to the authorship and/or publication of this article.

Authorship contributions: Concept - Ç.B., E.A.; Design Ç.B., E.A.; Supervision - Ç.B., E.A.; Data collection \&/or processing - Ç.B.; Analysis and/or interpretation - Ç.B.; Literature search - Ç.B.; Writing - Ç.B.; Critical review - Ç.B., E.A.

\section{References}

1. Serçekuş P, Göral Türkcü S. Women Diagnosed with Gynecologic Cancer Sexuality Problems and Nursing Applications. Dokuz Eylül Üniversitesi Hemşirelik Fakültesi Elektronik Dergisi 2015;8(1):36-8.

2. Pınar S, Algier L, Çolak M, Ayhan A. Jinekolojik Kanserli Hastalarda Yaşam Kalitesi. Uluslararası Hematoloji-Onkoloji Dergisi 2008;3(18):141-9.

3. Açıkgöz F. Cinsel sağlığa yönelik hemşirelik yaklaşım modelleri. Androloji Bülteni 2011;47:305-7.

4. Lamont J; CONTRIBUTING AUTHORS. Female sexual health consensus clinical guidelines. J Obstet Gynaecol Can 2012;34(8):769-75. [CrossRef]

5. Tuğut N, Gölbaşı Z. Öğrenci hemşirelere yönelik cinselliği değerlendirme bilgi testi’nin geliştirilmesi, geçerlik ve güvenirliği. Anadolu Hemşirelik ve Sağllk Bilimleri Dergisi 2013;16(3):148-53.

6. Hawkins Y, Ussher J, Gilbert E, Perz J, Sandoval M, Sundquist $\mathrm{K}$. Changes in sexuality and intimacy after the diagnosis and treatment of cancer: the experience of partners in a sexual relationship with a person with cancer. Cancer Nurs 2009;32(4):271-80. [CrossRef]

7. Terzioğlu F, Alan H. The Effect of Some Psychological Problems Experienced During Gynecological Cancer Treatment Upon Women's Sexual Life. Anadolu Hemşirelik ve Sağlık Bilimleri Dergisi 2015; 18(2):140-7.

8. Audette C, Waterman J. The sexual health of women 
after gynecologic malignancy. J Midwifery Womens Health 2010;55(4):357-62. [CrossRef]

9. Cleary V, Hegarty J. Understanding sexuality in women with gynaecological cancer. Eur J Oncol Nurs 2011;15(1):38-45. [CrossRef]

10. Tang CS, Lai BP, Chung TK. Influences of mastery, spousal support, and adaptive coping on sexual drive and satisfaction among chinese gynecologic cancer survivors. Arch Sex Behav 2010;39(5):1191-200.

11. Chun N. Effectiveness of PLISSIT model sexual pro- gram on female sexual function for women with gynecologic cancer. J Korean Acad Nurs 2011;41(4):471-80.

12. Nho JH. Effect of PLISSIT model sexual health enhancement program for women with gynecologic cancer and their husbands. J Korean Acad Nurs 2013;43(5):681-9. [CrossRef]

13.Zargar Shoushtari S, Afshari P, Abedi P, Tabesh H. The effect of face-to-face with telephone-based counseling on sexual satisfaction among reproductive aged women in Iran. J Sex Marital Ther 2015;41(4):361-7. 